\title{
Oxidation of a Commercial Nickel-Based Superalloy under Static Loading
}

\author{
B. J. FOSS, ${ }^{1}$ M. C. HARDY, ${ }^{1}$ D. J. CHILD, ${ }^{1}$ D. S. McPHAIL,${ }^{2}$ \\ and B. A. SHOLLOCK ${ }^{3,4}$
}

\begin{abstract}
1.-Rolls-Royce plc, Derby DE24 8BJ, UK. 2.-Department of Materials, Imperial College London, London SW7 2AZ, UK. 3.-WMG, University of Warwick, Coventry CV4 7AL, UK. 4.-e-mail: b.shollock@warwick.ac.uk
\end{abstract}

The current demands of the aviation industry for increased gas-turbine efficiency necessitate higher turbine entry temperatures, requiring that alloys exhibit superior oxidation resistance. The synergistic effects of oxidation and mechanical stresses pose a complex issue. The purpose of the current research was to examine the effects of stress on the oxidation and oxygen transport in a commercial nickel-based superalloy. Fine grain RR1000 in both polished and shot-peened conditions was studied for classic (zero load) and statically loaded conditions using integrated two-stage isotopic tracing combined with focusedion-beam secondary ion mass spectrometry (FIB-SIMS). $\mathrm{Cr}_{2} \mathrm{O}_{3}$ external oxide formed with semicontinuous $\mathrm{TiO}_{2}$ above and below. Preferential grain boundary $\mathrm{Al}_{2} \mathrm{O}_{3}$ internal oxide formation, $\gamma^{\prime}$-dissolution, and recrystallization occurred subsurface. Oxidation mechanisms were dominated by anionic/cationic growth in the external oxide with inward oxygen transport, initially through the partially unprotective external oxide, then along internal oxide/ alloy interfaces. Loading did not influence the oxidation products formed but did bring about expedited oxidation kinetics and changes to the oxide morphology. The oxygen diffusivity $D_{\mathrm{O}}^{*}\left(\times 10^{-13} \mathrm{~cm}^{2} \mathrm{~s}^{-1}\right)$ ranged from 0.39 for the polished alloy to 3.7 for the shot-peened condition under compressive stress. Arguably, the most significant effects took place in the subsurface regions. Increased oxidation kinetics were attributed to the development of fast cation diffusion paths as the alloy deformed by creep.

\section{INTRODUCTION}

Increased turbine entry temperatures (TETs) for improved turbine efficiency push Ni-based superalloys to their operational limits. Higher temperatures require excellent alloy degradation resistance in oxidizing environments to meet the operational service life of the component. Failure to meet this requirement results in excessive oxidation, which reduces the component's ability to maintain its mechanical integrity. The oxidation resistance will depend on the ability of the alloys to form, and maintain, a compact and adherent scale that will protect the alloy from further oxidation attack. ${ }^{1}$ Loss of the protective oxide scale becomes problematic as it exposes the parent alloy to further oxidation attack. Stresses in the oxide scale due to intrinsic growth stresses, thermal stresses, or externally applied stresses all increase the likelihood of scale failure. ${ }^{2,3}$ The influence of environmental factors on alloy stability at elevated temperatures is now of great importance, in both new alloy design, and those currently in service. The distinct characteristics of the oxide formed and its kinetics depend on several variables, including composition, microstructure, environment, temperature, and surface condition. The surface condition of the alloy plays an important role in its resistance against oxidationinduced damage. ${ }^{4,5}$ Shot-peening is a widely used surface treatment primarily sought for its ability to offset high mechanical loads at the surface, but shotpeening effects could be both beneficial and detrimental to an alloy's long-term integrity because the process itself imposes high levels of surface and subsurface deformation.

For disk applications, the composition of the class of nickel-based alloys normally permits the forma- 
tion of a continuous chromia healing layer beneath the transient oxides that rapidly form from the less noble alloy components. The formation of this layer should prevent further oxidation attack as it acts as a barrier between the metal and the exposure environment; however, further attack can occur at either the oxide/gas or the metal/oxide interfaces, if either the metal cations or oxygen anions penetrate the layer. The latter case is known as internal oxidation and is often the main cause of oxidation failures. ${ }^{6}$ In addition to the above, and of particular importance to nickel-based alloys, is the depletion of $\mathrm{Ni}_{3} \mathrm{Al}$ precipitate-forming elements from the alloy to form oxidation products themselves. Consequently, a subsurface depleted zone develops that ultimately weakens the near surface of the alloy and reduces the load bearing cross section of the component. Further consequences of compositional changes in the subsurface include void formation, volume changes, alloy-scale interface stability and phase transformations. Each of these relate to the different rates at which the various components in the alloy oxidize. In addition to this microstructural instability, as the oxide continues to grow, the stress required to crack the oxide decreases, ${ }^{2,3}$ and the likelihood of further exposure of the base alloy to the environment increases.

This investigation reveals the oxidation behavior of the fine-grain (FG) polycrystalline nickel superalloy fine grain RR1000 in both the polished shotpeened surface conditions at temperatures in the range $700-800^{\circ} \mathrm{C}$ both without applied load, termed classic oxidation conditions, and under a static bending load. The oxidation and oxidation-induced microstructural changes have been investigated using several analytical techniques and are discussed using the exposure at $800^{\circ} \mathrm{C}$ as an illustration in this article. The different methodologies have allowed for quantification and characterization of the governing mechanisms pertaining to the surface and subsurface oxidation processes.

\section{EXPERIMENTAL}

\section{Alloy}

The FG RR1000 material studied was produced via a powder metallurgy route followed by extrusion, forging, and a two-step heat treatment to achieve the desired fine-grained microstructure, $\gamma$ ' size and volume fraction. Table I gives the nominal alloy composition (in wt.\%) and reveals the various components added to maintain a combination of strength, damage tolerance, and creep resistance. ${ }^{7}$
Hardy et al. ${ }^{7}$ provided a detailed rationale for each of the elements added and their limitations in the alloy design.

\section{Oxidation Experiments}

Exposures made use of a customized isotopic exchange facility, which permitted careful control of the exposure environment. This particular setup facilitated the use of the ${ }^{18} \mathrm{O}_{2}$ isotope in two-stage isotopic exposure experiments. The samples were first exposed in research-grade oxygen (referred to as ${ }^{16} \mathrm{O}_{2}$ ) at $p \mathrm{O}_{2}=200$ mbar. The exchange furnace was reevacuated before introducing the ${ }^{18} \mathrm{O}_{2}$-enriched oxygen also at $p \mathrm{O}_{2}=200$ mbar. The samples were then quench-cooled in air by rolling off the exchange furnace. Bending oxidation under combined isotopic oxidation conditions used a bespoke bending rig based on a simple bent beam test where the load is applied to the ends of the test sample. All specimens were loaded to a nominal stress of $850 \mathrm{MPa}$, which is below the yield stress at $800^{\circ} \mathrm{C}$. To achieve the desired stress required application of the following relationship: ${ }^{8}$

$$
H=\frac{\sin \left(\frac{L \sigma}{k t E(T)}\right) \mathrm{k} t E(T)}{\sigma}
$$

where $H$ is the distance between two ends of the holder required to achieve the desired stress $\sigma ; L$ and $t$ are the length and thickness of the specimen, respectively; $E(T)$ is the Young's modulus at temperature $T$; and $\mathrm{k}$ is an empirical constant equal to 1.28. This relationship then states that achieving the desired load requires a measurement of $H$ only. Measurement of $H$ was accomplished using a calibrated digital Vernier caliper with an accuracy of $\pm 0.01 \mathrm{~mm}$. Table II provides the sample dimensions and holder separation as well as the elastic strain as calculated for the $850 \mathrm{MPa}$ applied stress and the Young's modulus for the $800^{\circ} \mathrm{C}$ exposures.

\section{Characterization}

Oxide cross-section preparation, imaging, and focused-ion-beam secondary ion mass spectrometry (FIB-SIMS) used an FEI FIB-200 SIMS workstation (FEI Company, Hillsboro, OR) equipped with a quadrupole detector as described by McPhail. ${ }^{9}$ Cross-sectioning applied various milling angles, ranging from $15^{\circ}$ to $30^{\circ}$ to the surface to produce ramped cross sections of the external oxide (EO) and oxidation-affected zone (OAZ). Note that the OAZ may contain internal oxidation (IO), $\gamma^{\prime}$-dissolution

Table I. Nominal composition of FG RR1000 in wt.\%

\begin{tabular}{lllllllllll}
\hline $\mathbf{A l}$ & $\frac{\mathbf{C o}}{18.5}$ & $\frac{\mathbf{C r}}{15}$ & $\frac{\mathbf{H f}}{0.5}$ & $\frac{\mathbf{M o}}{5.0}$ & $\frac{\mathbf{T a}}{2.0}$ & $\frac{\mathbf{T i}}{3.6}$ & $\frac{\mathbf{C}}{0.027}$ & $\frac{\mathbf{B}}{0.015}$ & $\frac{\mathbf{Z r}}{0.06}$ & $\frac{\mathbf{N i}}{\mathrm{Bal} .}$ \\
\hline
\end{tabular}


Table II. Material and loading parameters used in bending oxidation tests at $800^{\circ} \mathrm{C}$

\begin{tabular}{|c|c|c|c|c|}
\hline Surface finish & $L(\mathbf{m m})$ & $t(\mathbf{m m})$ & $\boldsymbol{H}(\mathbf{m m})$ & Strain, $\varepsilon(\%)$ \\
\hline Polished & 59.95 & 1.21 & 59.58 & 0.50 \\
\hline Shot-peened & 59.16 & 1.10 & 58.73 & 0.50 \\
\hline
\end{tabular}

Please refer to text for definition of the parameters

(GPD), and recrystallization (RX). Imaging used a 50-pA gallium primary ion beam current in both ion-induced secondary electron (IISEI) and total positive ion (TPII) modes with at least two cross sections analyzed at each temperature and time. The SIMS maps were collected for ${ }^{16} \mathrm{O}^{-}$and ${ }^{18} \mathrm{O}^{-}$ isotopes. Mapping used beam currents of 100$300 \mathrm{pA}$ depending on the sample analyzed; at these currents, the beam has a diameter 20-30 nm. A raster of $256 \times 221$ pixels achieved suitable lateral resolution for all specimens while limiting the beam-induced damage. Samples were also examined in a Zeiss Auriga (Carl Zeiss, Oberkochen, Germany) fitted with an Oxford Instruments SMax 80 EDX detector (Oxford Instruments, Oxfordshire, U.K.) to evaluate the oxide compositions.

\section{RESULTS}

\section{Classic Oxidation}

Ion imaging provided useful, complementary information from the sectioned samples. Figure 1 shows the typical oxide cross-sectional morphology of polished (Fig. 1a) and shot-peened (Fig. 1b) samples following exposure at $800^{\circ} \mathrm{C}$ for $120 \mathrm{~h}(72 \mathrm{~h}$ ${ }^{16} \mathrm{O}_{2}+48 \mathrm{~h}{ }^{18} \mathrm{O}_{2}$ ), whereas Fig. 2 presents a schematic diagram showing the features observed in the oxidized samples of FG RR1000. The micrographs demonstrate the similarity in the oxide morphologies produced between the two surface finishes; however, the severity of the oxidation damage incurred after shot-peening increases particularly in the subsurface region.

The external oxide growth observed in both the polished and shot-peened alloys follows that observed for other superalloys of similar compositions tested at equivalent temperatures. ${ }^{10-14}$ Energy-dispersive x-ray analyses showed that the overall oxide morphology from the external scale to internal oxides of $\mathrm{Cr}_{2} \mathrm{O}_{3} / \mathrm{TiO}_{2}$ in the outer scale to $\mathrm{Al}_{2} \mathrm{O}_{3}$ internally agrees with the expected thermodynamic behavior; however, and in contrast to the thermodynamic predictions, the alloy formed an outer layer of $\mathrm{TiO}_{2}$, believed to be at the expense of its oxidation resistance. ${ }^{14,15}$ Cationic diffusion is inferred from the known transport mechanisms for $\mathrm{Cr}_{2} \mathrm{O}_{3}$ growth 16,17 and from the fact that titanium must diffuse outwards to form above the outer scale. This requires titanium diffusion through the chromia and an adequate solubility of the chromium sublattice.

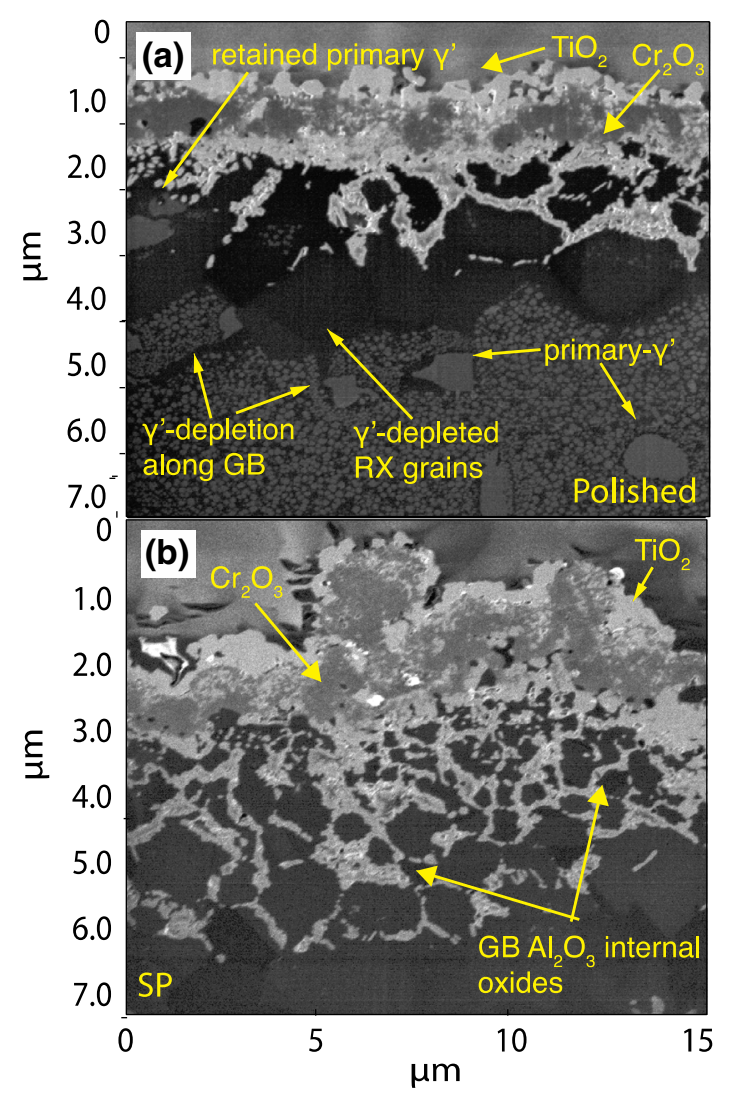

Fig. 1. Oxide cross sections of FGRR1000 following classic oxidation: (a) TPII polished and (b) TPII shot-peened after exposure $800^{\circ} \mathrm{C}$ for $120 \mathrm{~h}$.

In support of this, Naoumidis et al. ${ }^{18}$ previously reported a solubility of $18 \%$ on the chromium sublattice at $1000^{\circ} \mathrm{C}$. Although the temperatures are considerably higher than those examined in this article, titanium is still expected to have a large enough solubility to facilitate titanium diffusion to the surface.

FIB-SIMS mapping shows the relative distributions of the ${ }^{16} \mathrm{O}$ and ${ }^{18} \mathrm{O}$ species in the oxide cross sections for the image presented in Fig. 1a. The pixel intensities have been normalized to the maximum counts in each array. The ${ }^{16} \mathrm{O}^{-}$map following exposure at $800^{\circ} \mathrm{C}$ for $120 \mathrm{~h}$ represents the oxide growth that occurs in the first part of the two-stage exposure $(72 \mathrm{~h})$. The maps confirm the existence of the external scale with the internal oxides directly 


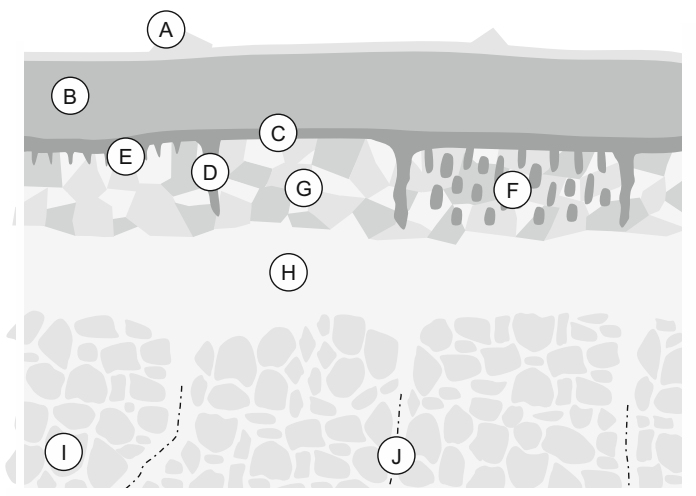

A. Rutile $\left(\mathrm{TiO}_{2}\right)$ outer scale/particles

B. Chromia scale

C. Alumina layer

D. Intergranular alumina fingers

E. Intragranular alumina fingers

F. Internal alumina islands

G. Recrystallised zone

H. Gamma-prime depleted zone

I. Gamma-prime particles

J. Grain boundary carbides

Fig. 2. Schematic diagram highlighting the features observed in oxidized FG RR1000.

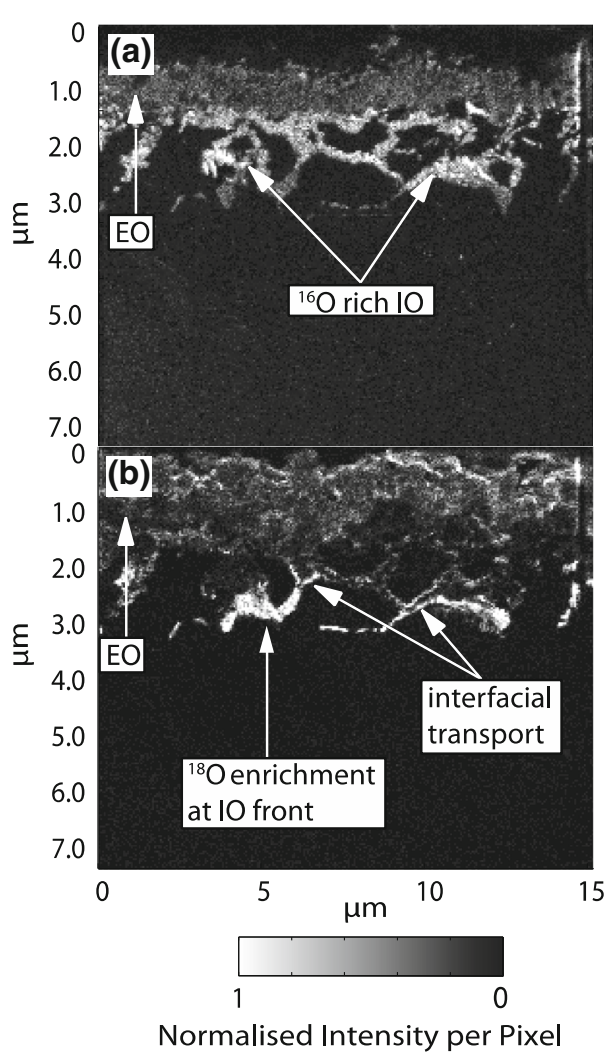

Fig. 3. FIB-SIMS elemental mapping: (a) ${ }^{16} \mathrm{O}^{-}$and (b) ${ }^{18} \mathrm{O}^{-}$of the oxide cross section given in Fig. 1a for the polished condition after exposure $800^{\circ} \mathrm{C}$ for $120 \mathrm{~h}$.

beneath in the base alloy. Note that the relative intensity of the ${ }^{16} \mathrm{O}^{-}$signals in internal oxide regions, compared with the external oxide, does not necessarily imply higher oxygen contents. Likewise, the ${ }^{18} \mathrm{O}^{-}$map (Fig. 3b) signifies the oxygen transport and oxide growth during the second half of the two-stage exposure $(48 \mathrm{~h})$. The proficiency of the FIB-SIMS mapping technique reveals the new oxide growth as well as the identifying short-circuit oxygen diffusion paths such as boundaries. ${ }^{19,20}$ FIBSSIMS mapping showed that inward anionic diffusion took place to form the internal oxides during the oxide growth for both surface conditions. A comparison of the ${ }^{16} \mathrm{O}^{-}$and ${ }^{18} \mathrm{O}^{-}$ion distributions at all temperatures studied indicated that the external scale contains ${ }^{18} \mathrm{O}$-rich regions at the surface and within the bulk external oxide. In the region of the external scale closest to the oxide/gas interface, the oxide is composed of mostly ${ }^{18} \mathrm{O}$, whereas in the region closest to the oxide-metal interface, the oxides contain a mixture of ${ }^{16} \mathrm{O}$ and ${ }^{18} \mathrm{O}$ species. This illustrates oxygen transport taking place through the external oxide to form new oxide at the alloy/ oxide interface, but at the same time new oxide forms at the gas/oxide interface, which relies on outward cation diffusion. Indeed, these findings agree with other studies, which previously revealed countercurrent mechanisms in growing chromia scales, ${ }^{16,17,21,22}$ which is consistent with the observations that the $\mathrm{Cr}_{2} \mathrm{O}_{3}$ normally grows through outward cationic growth (i.e., $p$-type behavior). ${ }^{16}$ Therefore, the oxide grows through simultaneous countercurrent transport of inwardly diffusing oxygen anions and outwardly diffusing titanium and chromium cations.

\section{Oxidation Under Bending Load}

Bending loads do not influence the nature of the oxidation products formed but do cause significant morphological changes in the shot-peened alloy derivative at $800^{\circ} \mathrm{C}$. The external bending load induced changes to the oxide morphology in both the polished (Fig. 4) and shot-peened (Fig. 5) samples following exposure at $800^{\circ} \mathrm{C}$ for $120 \mathrm{~h}$. In the case of the polished sample, for example, Fig. 4a outlines how the external oxides now form subsurface protrusions, consisting largely of $\mathrm{Cr}_{2} \mathrm{O}_{3}$.

As with the samples tested under classic oxidation conditions, shot-peened samples exhibited clear differences in the oxide and near-surface morphology under the influence of an external load compared to the polished samples, with the most notable morphological difference observed in the subsurface of the compressively loaded side of the bending specimen. Concerning the external oxide, 


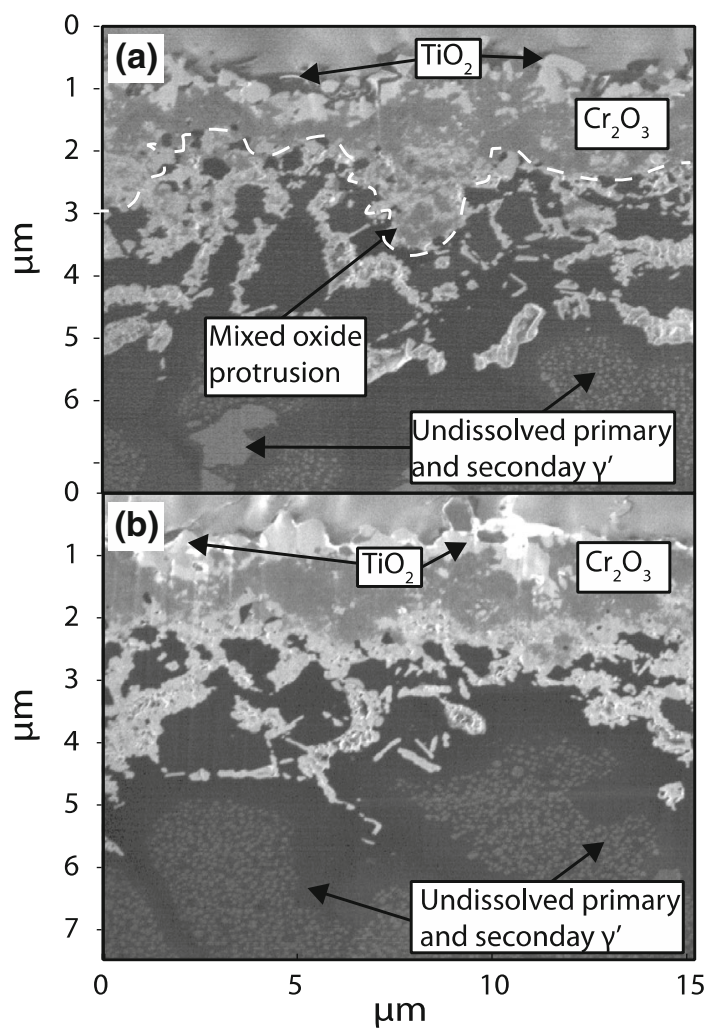

Fig. 4. Oxide cross sections of polished specimens under bending loads: (a) TPII compression and (b) TPII tension after exposure $800^{\circ} \mathrm{C}$ for $120 \mathrm{~h}$.

Fig. 4 shows that the alloy undergoes more extensive and continuous $\mathrm{TiO}_{2}$ formation under compressive loads. In the case of the shot-peened alloy (Fig. 5), a continuous oxide layer forms beneath the external oxide but separated from the external oxide by an intermediate internal oxidation/recrystallized layer. This continuous oxide layer forms under both loading conditions at $800^{\circ} \mathrm{C}$, but is more extensive under compression (Fig. 5a). The presence of such a layer does not prevent grain boundary internal oxide precipitation deeper into the alloy. Under compressive loads, isolated precipitates connect to the continuous oxide layer by fine ligaments. The tensile-loaded specimen exhibits relatively more extensive internal oxidation below this layer.

The ${ }^{16} \mathrm{O}^{-}$and ${ }^{18} \mathrm{O}^{-}$maps for each surface and loading condition confirm the countercurrent transport mechanism previously described for classic oxidation, with the example of the shot-peened sample given in Fig. 6 (compression) and Fig. 7 (tension). The ${ }^{18} \mathrm{O}^{-}$distribution throughout the entirety of the external oxide corroborates the inward oxygen (anionic) diffusion and outward cation diffusion to form the external $\mathrm{TiO}_{2}$ and $\mathrm{Cr}_{2} \mathrm{O}_{3}$ external scale. Anionic diffusion through the bulk alloy itself takes place initially along the grain boundaries of the parent alloy, where the internal oxides nucleate, with the interface of the grain boundary oxides and the parent/recrystallized grains providing a fast

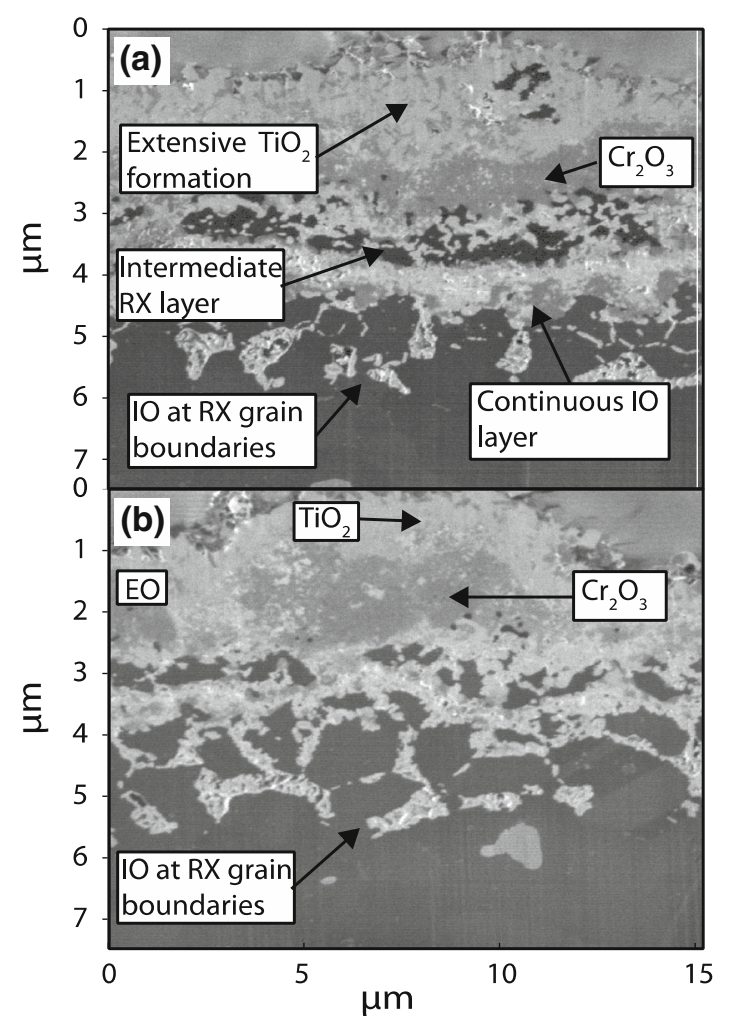

Fig. 5. Oxide cross sections of shot-peened FG RR1000 under bending loads: (a) TPII compression and (b) TPII tension after exposure $800^{\circ} \mathrm{C}$ for $120 \mathrm{~h}$.

diffusion path for oxygen transport in the alloy. As with the unloaded specimens, the enhanced oxygen diffusivity along these interfaces expedites the grain boundary internal oxidation rate. ${ }^{23-25}$

The overall depth of the scale and internal oxide region did not significantly differ between compression and tension for the shot-peened condition. The ${ }^{16} \mathrm{O}^{-}$map for the shot-peened compressive specimen (Fig. 6a), however, reveals a subtle difference in the normalized intensity across the external oxide. This is visualized as a layer of low ${ }^{16} \mathrm{O}^{-}$intensity (labelled 1) below a layer of higher ${ }^{16} \mathrm{O}^{-}$intensity (labeled 2); the dashed white line defines the interface of these two layers. This boundary coincides with the interface of the rutile and chromia layers seen in Fig. 5b and, therefore, relates to the different secondary ion yields of the chromia and rutile. The ${ }^{18} \mathrm{O}^{-}$map (Fig. $6 \mathrm{~b}$ ), however, does not demonstrate this layering. Below the external scale, the internal oxides that reside among the intermediate recrystallized layer demonstrate both ${ }^{16} \mathrm{O}$ and ${ }^{18} \mathrm{O}$ enrichment. The continuous layer is also separable into two layers of contrasting ${ }^{16} \mathrm{O}^{-}$intensity, where the dashed green line (Fig. 6a) defines the interface of these two regions; however, the region having the higher ${ }^{16} \mathrm{O}^{-}$ signal (labeled 3 ) sits above that of lower intensity area. As with the external oxide, the ${ }^{18} \mathrm{O}^{-}$distribution (Fig. 6b) does not show this separation in the 


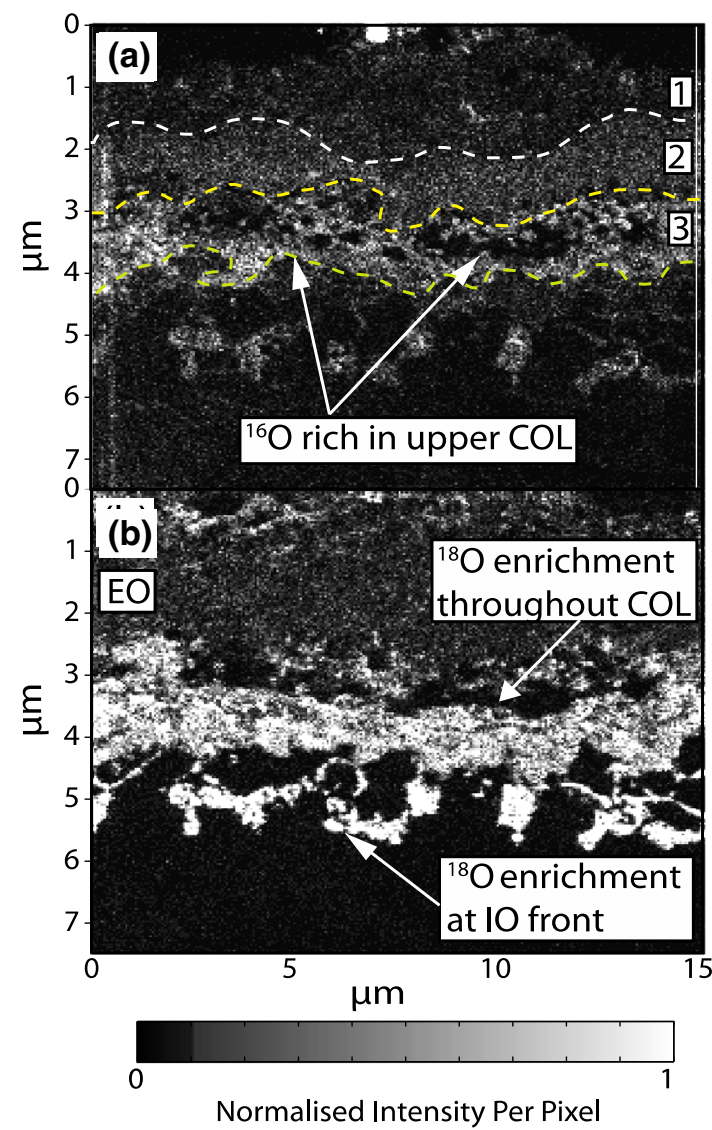

Fig. 6. FIB-SIMS elemental mapping: (a) ${ }^{16} \mathrm{O}^{-}$and (b) ${ }^{18} \mathrm{O}^{-}$of the compression oxide cross sections for the shot-peened sample given in Fig. $5 \mathrm{a}$ after exposure $800^{\circ} \mathrm{C}$ for $120 \mathrm{~h}$.

continuous layer. The sustained ${ }^{18} \mathrm{O}^{-}$signal in the grain boundary internal oxides illustrates the continued oxygen diffusion through the continuous layer. The ${ }^{16} \mathrm{O}^{-}$map corresponding to oxidation under tension (Fig. 7a) demonstrates a similar layering in the external oxide (see the dashed white line) but not in the continuous oxide layer. For both surface conditions, this layered structure indicates the temporal evolution of the structure, with the intermediate chromia-rich and $\mathrm{TiO}_{2}$ layers forming early in the exposure in both cases, with some internal oxides, particularly in the tension side. Internal oxides (Fig. 7b) form predominately in the second stage of the oxidation exposure, with the continuous layer in the compressive region (Fig. 7b).

\section{Oxygen Tracer Diffusion Coefficient in Exter- nal Oxide}

The oxygen tracer diffusion coefficient $D_{\mathrm{O}}^{*}$ in the external oxide was evaluated for all oxidation conditions using the ${ }^{16} \mathrm{O}^{-}$and ${ }^{18} \mathrm{O}^{-}$FIB-SIMS maps. An analysis used the isotopic fraction $v$ of the oxygen isotopes distribution, as this mitigates the spurious variations in signal intensity due to sample topography, localized charging, and instrumen-

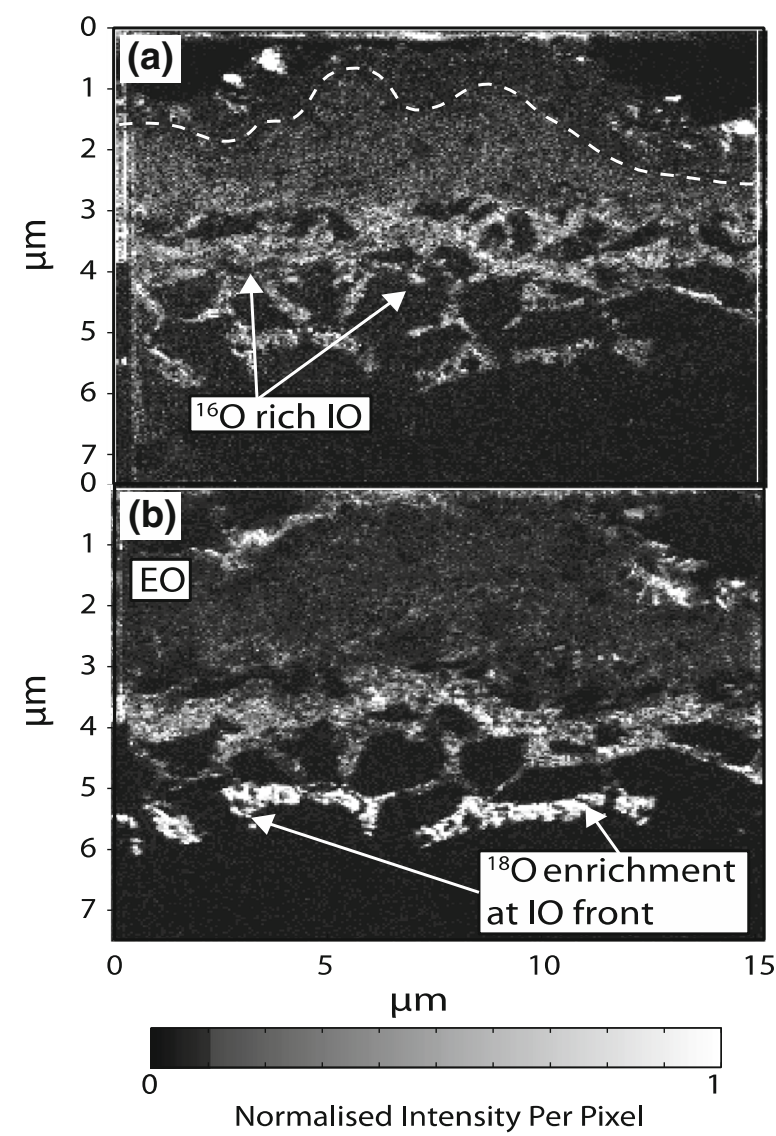

Fig. 7. FIB-SIMS elemental mapping: (a) ${ }^{16} \mathrm{O}^{-}$and (b) ${ }^{18} \mathrm{O}^{-}$of the tension oxide cross sections for the shot-peened sample given in Fig. $5 \mathrm{~b}$ after exposure $800^{\circ} \mathrm{C}$ for $120 \mathrm{~h}$.

tal factors. Neglecting the contribution from ${ }^{17} \mathrm{O}^{-}$, the isotopic fraction was calculated as:

$$
v=\frac{{ }^{18} \mathrm{O}^{-}}{\left[{ }^{16} \mathrm{O}^{-}+{ }^{18} \mathrm{O}^{-}\right]}
$$

where ${ }^{16} \mathrm{O}^{-}$and ${ }^{18} \mathrm{O}^{-}$are the ${ }^{16} \mathrm{O}^{-}$and ${ }^{18} \mathrm{O}^{-}$intensities obtained from the FIB-SIMS maps. The application of Eq. 2 on a pointwise basis produced isotopic fraction (IF) maps, which indicated regions of ${ }^{18} \mathrm{O}$ enrichment. Because the maps are also $m \times n$ elemental arrays containing the spatial distribution and the intensities of the ${ }^{16} \mathrm{O}^{-}$and ${ }^{18} \mathrm{O}^{-}$species, it was possible to compute isotopic enrichment depth profiles (IEDPs). IEDPs were computed using an integrated line scan (ILS) method in MATLAB. This method computes the average of the integrated secondary ion intensity for a line scan width of $N$ pixels at each depth increment $x$, to give a column vector $C(x)$. Mathematically, this may be represented as:

$$
C(x)=\frac{1}{N} \frac{\sum_{n}^{N} 18 \mathrm{O}^{-}}{\left[\sum_{n}^{N} 16 \mathrm{O}^{-}+\sum_{n}^{N} 18 \mathrm{O}^{-}\right]} .
$$

Finally, $D_{\mathrm{O}}^{*}$ was estimated by fitting the profiles (using a nonlinear least-squares method) according 

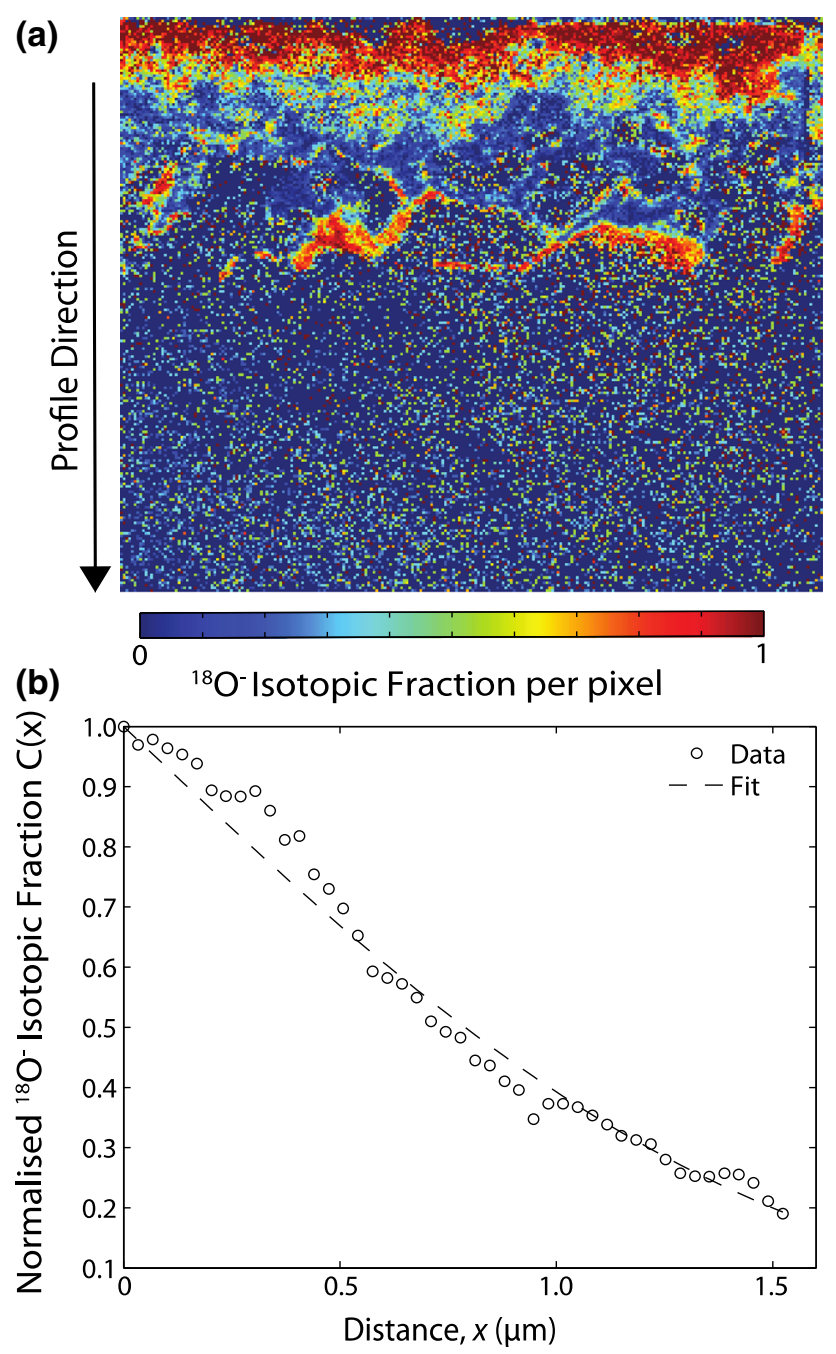

Fig. 8. Example determination of oxygen tracer diffusion in external oxide using FIB-SIMS data for polished FG RR1000 oxidized under classic conditions: (a) ${ }^{18} \mathrm{O}^{-}$isotopic fraction map and (b) fitted isotopic enrichment profile. to Fick's second law of diffusion for a semi-infinite media with a constant source: ${ }^{26}$

$$
C^{\prime}(x)=\frac{C(x)-C_{b g}}{C_{g}-C_{b g}}=\operatorname{erfc}\left(\frac{x}{2 \sqrt{D_{O}^{*} t_{18}}}\right)
$$

where $C^{\prime}(x)$ is the isotopic fraction normalized to the tracer natural isotopic abundance $C_{b g}(0.24 \%)$, and the tracer gas phase concentration $C_{g}(97.0 \%), x$ is the distance from the surface, and $t_{18}$ is the ${ }^{18} \mathrm{O}_{2}$ exposure time. Figure 8 shows this method applied to the polished alloy oxidized under classical conditions (i.e., Figure $1 \mathrm{a}$ and b), giving both the IF map and the fitted isotopic enrichment profile for the external oxide.

Table III lists the tracer diffusion coefficients calculated for classical and bending load specimens in both the polished and shot-peened conditions.

The values should be treated as effective diffusion coefficients as they account for both the bulk and grain boundary diffusivities. As shown, the shotpeened specimens consistently show higher diffusivities than the polished specimens. The bending loads appear to have only a small influence on the diffusivities, which increase by less than an order of magnitude for all examples. Importantly, the coefficients here agree with the apparent oxygen diffusion coefficients measured for $\mathrm{Cr}_{2} \mathrm{O}_{3}$ scales grown on $\mathrm{Ni}-30 \mathrm{Cr}$ alloys at the same temperature. ${ }^{17}$

\section{Oxidation Damage}

Depth measurements of the external scale, internal oxide, and $\gamma$ '-depleted/recrystallized region clearly highlighted the stress-related effects during oxidation under compressive and tensile loading. These stress effects do not portray straightforward relationships, and therefore, Table III interprets the load effects in terms of depth enhancement ratios $R$, the absolute depth increase $\Delta$, and relative

Table III. Comparison of various kinetic parameters for classical, tensile loading and compressive loading

\begin{tabular}{|c|c|c|c|}
\hline Parameter & Specimen & Polished & Shot-Peened \\
\hline \multirow[t]{3}{*}{$D_{O}^{*}\left(\times 10^{-13} \mathrm{~cm}^{2} \mathrm{~s}^{-1}\right)$} & Classical & 0.39 & 1.4 \\
\hline & Compression & 0.62 & 3.7 \\
\hline & Tension & 0.41 & 3.4 \\
\hline \multirow[t]{3}{*}{$R_{\text {comp }}$ or $\Delta_{\text {comp }}(\mu \mathrm{m})$} & EO & $1.48(0.58)$ & $1.01(0.02)$ \\
\hline & $\mathrm{IO}$ & $1.51(1.48)$ & $1.09(0.17)$ \\
\hline & GPD/RX & $1.50(2.00)$ & $1.09(0.65)$ \\
\hline \multirow{3}{*}{$R_{\text {ten }}(\%)$ or $\Delta_{\text {ten }}(\mu \mathrm{m})$} & EO & $1.29(0.35)$ & $1.03(0.06)$ \\
\hline & IO & $1.38(1.13)$ & $1.06(0.28)$ \\
\hline & GPD/RX & $1.40(1.58)$ & $1.07(0.51)$ \\
\hline \multirow{2}{*}{$R_{\mathrm{IOA}}$} & Compression & 1.76 & 1.34 \\
\hline & Tension & 1.47 & 1.08 \\
\hline
\end{tabular}

The subscripts comp. and ten.-applied to $\mathrm{R}$ and $\Delta$-indicate values for compression or tension, respectively. For the relative depth increase (R), the values in parenthesis are the absolute increase (i.e., $\Delta_{\text {ten }}$ or $\Delta_{\text {comp }}$ ) 
internal oxide area increase $R_{\mathrm{IOA}}$ for both polished and shot-peened specimens.

The polished specimens are most affected by the application of either compressive or tensile loads. This applies to all the parameters measured with the GPD/RX exhibiting both the greatest relative ( $\sim 50 \%$ in compression) and absolute depth increases. Compressive loads have the greatest influence on the oxidation damage with relative increases of $\sim 50 \%$ for all damage parameters with the exception of the IO area where a $76 \%$ increase occurs. In contrast, the shot-peened specimens appear to be less influenced by the applied loads. Nearly all of the damage parameters demonstrate an increase less than $10 \%$. Under compression, the internal oxide depth increases only slightly; however, the internal oxide area increases by $34 \%$. Note that this specimen also revealed significant changes in the internal oxide morphology.

\section{DISCUSSION}

Induced internal stresses from shot-peening under classic oxidation conditions and external loading of polished samples modify the nature of the external and internal oxides and/or accelerates the oxidation kinetics. The difference in oxide morphologies comes as a surprise given that most of the current literature only reports expedited kinetics. $^{27-32}$ The isotopic tracer experiments indicated that shot-peening and applied stresses have very little influence on the inward oxygen diffusion, thus eliminating enhancement due to a greater contribution from inward anionic growth. This suggests that the shot-peening and mechanical loads applied to polished samples act to influence the diffusivity of the oxidized solute species (i.e., chromium and titanium) in the parent and recrystallized alloy, ${ }^{33-35}$ and this is proposed to result from defects induced from creep deformation. This could explain the increased internal oxidation kinetics realized in the polished specimens under load. This appears to contradict much of the literature available (see for example, Refs. ${ }^{27,36,37}$ ), which infers the greater penetration depths from stress-assisted grain boundary diffusion. The premise of this argument states that the hydrostatic stress increases the oxygen diffusivity. For example, modeling conducted by Karabela et al. ${ }^{27,28}$ described accelerated internal oxidation kinetics by first computing the hydrostatic stress gradient through crystal plasticity modeling and then the oxygen diffusion. The authors successfully rationalized the amplified oxygen penetration depths through this method; however, this analysis did not account for flux of the metallic species and the oxidation processes themselves, which inherently modify the media in which the oxygen diffuses through. Furthermore, the approach itself implies that a compressive stress gradient should have a reverse effect and decrease the inward oxygen flux. Clearly, this is not consistent with the current study as compressive stresses generated increased internal oxidation penetration depths. The increased penetration depths presumably result from enhanced aluminum diffusion in the alloy, like the chromium and titanium to form the surface oxides. In support of this, both compression and tension sides demonstrate relatively higher $\gamma^{\prime}$-dissolution/recrystallization depths under load, indicative of an increased aluminum flux toward the internal oxidation front. To maintain internal oxide growth, the oxygen flux would have to equal that of the solute at the precipitation front to maintain the mass balance. SIMS mapping demonstrated a buildup of ${ }^{18} \mathrm{O}$ at an already established ${ }^{16} \mathrm{O}$ internal oxide front due to rapid surface diffusion along the internal oxide/alloy interface. Then, it is reasonable to assume that the internal oxidation front is already saturated with oxygen, so the oxygen potential is high enough for continued oxide precipitation. Hence, although the stress may influence the oxygen diffusion, the stresses could have a negligible effect with an already rapid surface diffusion taking place.

In the shot-peened specimens, a very different response occurs under external loads, which reflects the number of competing microstructural processes. The applied stresses did not increase the oxidation kinetics in the polished alloy above those of the shotpeened alloy. Even with defect annihilation in the shot-peened structure, it appears that the overall number defects reaches equilibrium. As such, the shot-peened alloy realizes no further enhancement of the oxidation kinetics at $800^{\circ} \mathrm{C}$, but significant morphological changes to the oxide microstructure occur.

\section{ACKNOWLEDGMENTS}

B.J.F. would like to acknowledge the support of the U.K. Engineering and Physical Sciences Research Council (EPSRC) and Rolls-Royce plc for financial support of his PhD research. BAS would like to thank the Royal Society and Rolls-Royce plc for her Industry Fellowship.

\section{OPEN ACCESS}

This article is distributed under the terms of the Creative Commons Attribution License which permits any use, distribution, and reproduction in any medium, provided the original author(s) and the source are credited.

\section{REFERENCES}

1. M. Brady, I. Wright, and B. Gleeson, JOM 52 (1), 16 (2000).

2. H. Evans, Int. Mater. Rev. 40, 1 (1995).

3. P. Hancock and J.R. Nicholls, Mater. High Temp. 12, 209 (1994).

4. J. Evans, J. Mater. Eng. Perform. 19, 1001 (2010).

5. S. Cruchley, M. Taylor, H. Evans, P. Bowen, M. Hardy, and S. Stekovic, Superalloys 2012, eds., E.S. Huron, R.C. Reed. M.C. Hardy, M.J. Mills, R.E. Montero, P.D. Portella, and J. Telesman (Warrendale, PA: TMS, 2012), p. 751

6. D.J. Young, High Temperature Oxidation and Corrosion of Metals, 1st ed. (Amsterdam: Elsevier Science Ltd., 2008), p. 247. 
7. M. Hardy, B. Zirbel, G. Shen, and R. Shankar, Superalloys 2004, eds., K.A. Green, H. Harada, T.E. Howson, T.M. Pollock, R.C. Reed, J.J. Shirra, and S. Walston (Warrendale, PA: TMS, 2004), p. 83.

8. A.J. Sedriks, Corrosion Testing Made Easy: Stress Corrosion Cracking Test Methods, Vol. 1 (Houston: National Association of Corrosion Engineers, 1990).

9. D. McPhail, R.J. Chater, and L. Li, Microchim. Acta 161, 387 (2008).

10. A. Encinas-Oropesa, G. Drew, M. Hardy, A. Leggett, J. Nicholls, and N.J. Simm, Superalloys 2008, eds., R.C. Reed, K.A. Green, P. Caron, T. Gabb, M.G. Fahrmann, E.S. Huron, and S.A. Woodard (Warrendale, PA: TMS, 2008), p. 609.

11. C.K. Sudbrack, S.L. Draper, T.T. Gorman, J. Telesman, T.P. Gabb, and D.R. Hull, Superalloys 2012, eds., E.S. Huron, R.C. Reed. M.C. Hardy, M.J. Mills, R.E. Montero, P.D. Portella, and J. Telesman (Warrendale, PA: TMS, 2012), p. 863.

12. M. Taylor, H. Evans, S. Stekovic, and M. Hardy, Mater. High Temp. 29, 145 (2012).

13. L. Zheng, M. Zhang, and J. Dong, Appl. Surf. Sci. 256, 7510 (2010).

14. J. Chen, P. Rogers, and J. Little, Oxid. Met. 47, 381 (1997).

15. S. Cruchley, H. Evans, M. Taylor, M. Hardy, and S. Stekovic, Corros. Sci. 75, 58 (2013).

16. S. Tsai, A. Huntz, and C. Dolin, Oxid. Met. 43, 581 (1995).

17. S.C. Tsai, A.M. Huntz, and C. Dolin, Mater. Sci. Eng., A 212, 6 (1996).

18. A. Naoumidis, H. Schulze, W. Jungen, and P. Lersch, J. Eur. Ceram. Soc. 7, 55 (1991).

19. A. Alibhai, R. Chater, D. McPhail, and B.A. Shollock, Appl. Surf. Sci. 203, 630 (2003).
20. T. Ooi, D. McPhail, R. Chater, and B.A. Shollock, Surf. Coat. Technol. 201, 3885 (2006).

21. A. Huntz and S. Tsai, J. Mater. Sci. Lett. 13, 821 (1994).

22. A. Huntz, J. Balmain, S. Tsai, K. Messaoudi, M. Loudjani, B. Lesage, and J. Li, Scripta Mater. 37, 651 (1997).

23. Y. Shida, F. Stott, B. Bastow, D. Whittle, and G. Wood, Oxid. Met. 18, 93 (1982).

24. D. Whittle, Y. Shida, G. Wood, F. Stott, and B. Bastow, Philos. Mag. A 46, 931 (1982).

25. F. Stott, Y. Shida, D. Whittle, G. Wood, and B. Bastow, Oxid. Met. 18, 127 (1982).

26. J. Crank, The Mathematics of Diffusion, 2nd ed. (London: Oxford University Press, 1980), p. 20.

27. A. Karabela, L. Zhao, B. Lin, J. Tong, and M. Hardy, Mater. Sci. Eng., A 567, 46 (2013).

28. A. Karabela, L.G. Zhao, J. Tong, N.J. Simms, J.R. Nicholls, and M.C. Hardy, Mater. Sci. Eng., A 528, 6194 (2011).

29. G. Calvarin Amiri, A. Huntz, and R. Molins, Mater. High Temp. 18, 91 (2001).

30. G. Calvarin-Amiri, A. Gourgues, A. Huntz, and R. Molins, Mater. Sci. Eng., A 298, 200 (2001).

31. G. Calvarin-Amiri, R. Molins, and A. Huntz, Oxid. Met. 53, 399 (2000).

32. A.M. Limarga and D.S. Wilkinson, Acta Mater. 55, 251 (2007).

33. D. Caplan and M. Cohen, Corros. Sci. 6, 321 (1996).

34. F. Wang, Oxid. Met. 48, 215 (1997).

35. R. Naraparaju, Corros. Eng., Sci. Technol. 44, 211 (2009).

36. L.G. Zhao, J. Eng. Mater. Technol. 133, 031002 (2011).

37. U. Krupp, Int. Mater. Rev. 50, 83 (2005). 